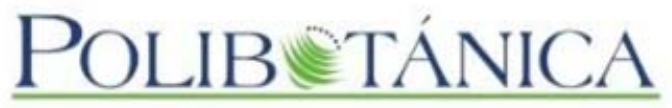

\title{
Polibotánica
}

ISSN electrónico: 2395-9525

polibotanica@gmail.com

Instituto Politécnico Nacional

México

http://www.polibotanica.mx

\section{ECOFISIOLOGÍA Y BIOQUÍMICA DE Salicornia bigelovii (TORR.) POR EFECTO DE QUITOSANO-AIB BAJO CONDICIONES DEL DESIERTO DE SONORA.}

\section{ECOPHYSIOLOGY AND \\ BIOCHEMISTRY OF Salicornia bigelovii (TORR.) BY EFFECT OF CHITOSAN- AIB EFFECT UNDER SONORA DESERT CONDITIONS.}

López-Corona, B.E., I. Mondaca-Fernández，P. Gortáres-Moroyoqui， M.M. MezaMontenegro, J. de J. Balderas-Cortés, C. Ruíz-Alvarado y E.O. Rueda-Puente.

ECOFISIOLOGÍA Y BIOQUÍMICA DE Salicornia bigelovii (Torr.) POR EFECTO DE QUITOSANO-AIB BAJO CONDICIONES DEL DESIERTO DE SONORA. ECOPHYSIOLOGY AND BIOCHEMISTRY OF Salicornia bigelovii (TORR.) BY EFFECT OF CHITOSAN-AIB EFFECT UNDER SONORA DESERT CONDITIONS.

\section{POLIBETANICA}

Instituto Politécnico Nacional
Núm. 49: 75-92 México. Enero 2020

DOI: $10.18387 /$ polibotanica.49.5

(c) (†) Este es un artículo de acceso abierto bajo la licencia Creative Commons 4.0 Atribución-No Comercial (CC BY-NC 4.0 Internacional). 


\section{ECOFISIOLOGÍA Y BIOQUÍMICA DE Salicornia bigelovii (Torr.) POR EFECTO DE QUITOSANO-AIB BAJO CONDICIONES DEL DESIERTO DE SONORA.}

\section{ECOPHYSIOLOGY AND BIOCHEMISTRY OF Salicornia bigelovii (TORR.) BY EFFECT OF CHITOSAN-AIB EFFECT UNDER SONORA DESERT CONDITIONS.}

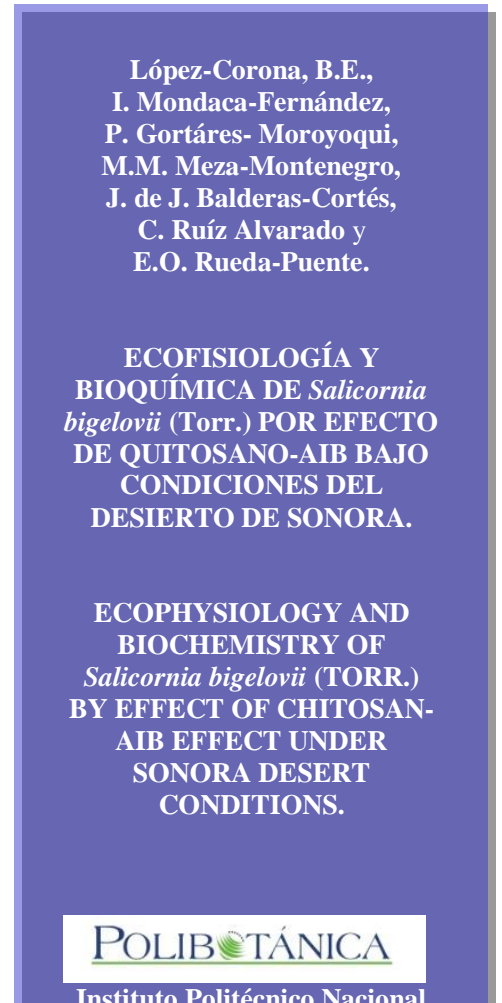

Instituto Politécnico Nacional

Núm. 49: 75-92 Enero 2020

DOI:

10.18387/polibotanica.49.5

\author{
B.E. López-Corona \\ I. Mondaca-Fernández \\ P. Gortáres- Moroyoqui \\ M.M. Meza-Montenegro \\ J. de J. Balderas-Cortés \\ Instituto Tecnológico de Sonora (ITSON) \\ Ciudad Obregón, Sonora, México. \\ C. Ruíz Alvarado \\ Instituto de Ciencias Agrícolas, Universidad Autónoma de Baja California
}

E.O. Rueda-Puente / erueda04@ santana.uson.mx Universidad de Sonora, Departamento de Agricultura y Ganadería, Hermosillo, Sonora, México.

RESUMEN: Salicornia bigelovii es una halófita de gran interés para la agroindustria por ser una fuente rica en proteína (> 14\%). En condiciones de campo, su cultivo no ha sido del todo funcional dado el bajo porcentaje de germinación. Asimismo, para obtener producciones altas de materia vegetal, es necesaria la incorporación de fuentes de nitrógeno, acudiendo a grandes cantidades de fertilización química y agudizando el problema de la salinidad. Actualmente los sistemas de producción sustentable en halófitas, demandan agroinsumos orgánicos; una alternativa a la fertilización química son los desechos a base de exoesqueletos y cascaras de camarón, de los cuales se pueden obtener subproductos de gran valor como el quitosano. El quitosano tiene múltiples aplicaciones entre ellas el uso como promotor en cultivos agrícolas mejorando el proceso de germinación, los rendimientos de la cosecha, la adsorción de micronutrientes y estimulando el mecanismo de defensa de las plantas y la formación de barreras físicas. En el presente estudio fue evaluado el quitosano al 50 y $100 \%$ de pureza, obtenido de exoesqueletos de camarón vs el promotor de crecimiento ácido indol butírico (AIB) al 0.937 y $1.25 \mathrm{~g} \mathrm{~kg}^{-1}$, además de mezclas de ambos productos y concentraciones, bajo condiciones de campo del desierto sonorense. Se evaluaron las variables de longitud radicular, altura de planta, peso seco y peso fresco de planta y sistema radicular, nitratos en savia, porcentaje de floración y análisis bromatológicos de planta completa. Los resultados obtenidos muestran que la aplicación del bioproducto quitosano (QUI) de origen marino conjuntamente con AIB (QUI 100\%AIB $\left.0.937 \mathrm{~g} \mathrm{~kg}^{-1}\right)$, presentó un efecto estimulante $(\mathrm{P}<0.05)$ en las variables del desarrollo radicular y crecimiento de planta, además de características bioquímicas, incluyendo proteína total, ceniza y lípidos totales en tallo, raíz y fracción aérea. La aplicación del quitosano potencia su efecto bioestimulante en sinergia con AIB. Este es el primer informe de quitosano como un bioproducto estimulante en asociación con AIB en Salicornia bigelovii.

Palabras clave: Halófitas, promotores de crecimiento, esquejes, bioproducto. 
ABSTRACT: Salicornia bigelovii is a halophyte of great interest for agribusiness because it is a rich source of protein (> 14\%). Under field conditions, its cultivation has not been fully functional given the low germination percentage. Likewise, in order to obtain high plant matter productions, the incorporation of nitrogen sources is necessary, resorting to large amounts of chemical fertilization and exacerbating the salinity problem. Currently, sustainable production systems in halophytes demand organic agro-inputs; An alternative to chemical fertilization is waste from exoskeletons and shrimp shells, from which valuable by-products such as chitosan can be obtained. Chitosan has multiple applications including the use as a promoter in agricultural crops, improving the germination process, crop yields, micronutrient adsorption and stimulating the defense mechanism of plants and the formation of physical barriers. In the present study, chitosan was evaluated at 50 and $100 \%$ purity, obtained from shrimp exoskeletons vs the indole butyric acid (AIB) growth promoter at 0.937 and 1.25 $\mathrm{g} \mathrm{kg}^{-1}$, in addition to mixtures of both products and concentrations, under field conditions of the Sonoran Desert. The variables of root length, plant height, dry weight and fresh weight of plant and root system, nitrates in sap, flowering percentage and bromatological analyzes of the whole plant were evaluated. The results obtained show that the application of the chitosan bioproduct (QUI) of marine origin together with AIB $\left(100 \%\right.$ QUI -AIB $\left.0.937 \mathrm{~g} \mathrm{~kg}^{-1}\right)$, presented a stimulating effect $(\mathrm{P}<0.05)$ in the variables of root development and growth of plant, in addition to biochemical characteristics, including total protein, ash and total lipids in stem, root and aerial fraction. The application of chitosan enhances its biostimulant effect in synergy with AIB. This is the first report of chitosan as a stimulant bioproduct in association with AIB in Salicornia bigelovii.

Key words: Halophytes, growth promoters, cuttings, bioproduct.

\section{INTRODUCCIÓN}

Debido a los altos contenidos de proteína (> 14\%) de la halófita Salicornia bigelovii y a las limitadas exigencias como cultivo para su producción, actualmente es una fuente de gran interés para múltiples agro-industrias, entre las que se destacan la producción de forraje y de alimento humano (Rueda Puente et al., 2009). Esta planta tolerante a la salinidad, se desarrolla de manera natural en la zona costera del desierto sonorense (Morzaria \& Barocio, 2008).

Actualmente, existe un marcado interés en promover e implementar el cultivo de S. bigelovii bajo un sistema de producción sustentable en las regiones costeras áridas y semiáridas de México (Burboa et al., 2017). Sin embargo, su cultivo presenta algunas desventajas, entre las que figura el bajo porcentaje de germinación, una alternativa de solución es la propagación por esquejes.

La técnica de esquejes consiste en separar una parte de una planta madre del tallo (raíz, hoja o tallo) y colocarla en condiciones ambientales favorables para inducir la formación de raíces y biomasa aérea, produciendo así una nueva planta independiente (González \& Arbo, 2006; López-Corona et al., 2019); una limitante de esta técnica radica en la dificultad para producir raíces funcionales (Jordán \& Casaretto, 2006), por lo que ciertos reguladores de crecimiento vegetal como el ácido naftalenacético (ANA), ácido indol acético (AIA) y ácido indol butírico (AIB) son utilizados para inducir con éxito la formación de raíces en esquejes (Jordán \& Casaretto, 2006).

Otro factor importante que influye en los rendimientos obtenidos en cultivos de Salicornia bigelovii, son las altas cantidades de fertilizante nitrogenado requeridas, recurriendo el productor a la fuente química, pero agudizando el problema de la salinidad, el cual es un factor abiótico que agrava la agricultura convencional en las zonas árido desérticas (Mazuela Águila, 2013). Una solución viable a dicha problemática es el uso de fertilizantes a base de compuestos naturales como fuentes vegetales e incluso fuentes de origen marino.

A través del tiempo, el uso de compuestos de fuentes marinas ha sido estudiado. Dado el gran potencial bioactivo que presentan son una fuente viable para sustituir compuestos químicos (Alvarado et al., 2019; Hernández Herrera, Santacruz, Briceño, Di Filippo, \& Hernández, 2018; López Ortega, Vhymeister, \& Rodríguez, 2018; Murrieta et al., 2015). 
Aunado a lo anterior, la problemática por los altos índices de contaminación en los mares del mundo es una preocupación constante y en algunos casos depende en gran medida de la tecnología usada en los diferentes procesos de industrialización de productos marinos y del manejo y disposición de los desechos.

Cerca del $75 \%$ - $85 \%$ del peso vivo de cangrejos y camarones capturados es desechado (conchas, cabezas y patas), mismos que se convierten en una carga económica para las industrias procesadoras, porque su eliminación es problemática y costosa (Gildberg \& Stenberg, 2001), por lo que comúnmente son arrojados al mar. Una de las alternativas para esta problemática es el aprovechamiento de estos "desechos" de los cuales se pueden obtener subproductos de gran valor como enzimas, proteínas, quitina y quitosano.

La quitina es un compuesto que se encuentra distribuido ampliamente en la naturaleza, después de la celulosa es el polímero natural más abundante (Plascencia Jatomea, Olvera, Arredondo, Hall, \& Shirai, 2002), presenta una tasa de reposición tan alta en la biósfera que se estima duplica a la de la celulosa, por lo que constituye un importante recurso renovable.

La principal fuente de quitina son exoesqueletos de crustáceos, particularmente, los exoesqueletos de camarón contienen una alta concentración de quitina, de la cual es posible obtener quitosano a través de un proceso químico de N-desacetilación.

El quitosano es un biopolímero lineal de alto peso molecular que va desde los 10,000 a 1,000,000 de Daltón. Es un compuesto biodegradable, no tóxico, biocompatible, semipermeable y con grandes propiedades. Todas las características del quitosano además de su carga positiva, le confiere potenciales aplicaciones en diversos campos (Xu, Hein, \& Wang, 2008), además de las múltiples propiedades biológicas que se le han atribuido, como antimicrobiana, antioxidante, antiinflamatorio, antifúngico, entre otros (Devlieghere, Vermeulen, \& Debevere, 2004; Hewajulige, Sivakumar, Sultanbawa, Wijesundera, \& S., 2007; Liu, Tian, Meng, \& Xu, 2007).

En estudios recientes el quitosano se ha utilizado como biofertilizante en diferentes tipos de cultivos como el maíz (Peña Datoli, 2016), el tabaco (González Gómez et al., 2017), el arroz (Molina Zerpa, Colina, Rincón., \& Vargas, 2017), la orquídea (Vera Alvarado \& Parismoreno, 2017), mejorando el proceso de germinación, enraizamiento, producción del follaje de la planta, los rendimientos de la cosecha y adsorción de micronutrientes y estimulando el mecanismo de defensa de las plantas y la formación de barreras físicas (Bernadette Dima., 2014; Hadwiger, Fristensky, \& Riggleman, 1984).

En Salicornia, se ha analizado el efecto bioestimulante [sustancia que al ser aplicada en cantidades pequeñas en la planta genera un impacto positivo en la germinación, desarrollo, crecimiento vegetativo, floración y desarrollo de los frutos (Saborío, 2002)] de la interacción plantamicroorganismo (Bashan et al., 2000; Rueda Puente et al., 2009), sin embargo no se ha estudiado el efecto de quitosano, el cual podría ser una alternativa favorable para mejorar las características agronómicas y de crecimiento de la Salicornia, además de contribuir a balancear el ciclo del $\mathrm{CO}_{2}$ de la tierra teniendo un impacto positivo en el efecto de invernadero (Rueda Puente et al., 2011).

Un mejoramiento en las características propias de la planta y en su rendimiento a base de quitosano, le darían un valor agregado a este cultivo y aumentaría su rentabilidad, haciéndola más atractiva para diferentes sectores. Es por lo anterior que, en el presente estudio fue evaluado el quitosano al 50 y $100 \%$ de pureza, obtenido de exoesqueletos de camarón vs el promotor de crecimiento AIB, además de mezclas de ambos productos y concentraciones, bajo condiciones de campo en el desierto sonorense.

\section{MATERIAL Y MÉTODOS}

\section{Área de estudio}

El proceso experimental fue desarrollado en el noroeste de México; área experimental del Departamento de Agricultura de la Universidad de Sonora y ubicada entre los paralelos $28^{\circ} 22^{\prime}$ y $29^{\circ}$ 
$25^{\prime}$ de latitud Norte y los meridianos $111^{\circ}$ y $112^{\circ} 25^{\prime}$ de longitud oeste con una altitud promedio de 70 metros sobre el nivel del mar. La temperatura ambiental, media alta en los meses de julio-agosto, oscila entre los $47 \pm 3{ }^{\circ} \mathrm{C}$, con una humedad relativa no mayor al $20 \%$.

\section{Obtención de quitosano}

Para la extracción del quitosano se utilizaron exoesqueletos de camarón obtenidos en industrias procesadoras, los cuales se redujeron a un tamaño de partícula menor a $250 \mu \mathrm{m}$ utilizando un tamiz. Para este proceso se siguió la metodología propuesta por (Hernández Cocoletzi, Águila Almanza, Flores Agustin, Viveros Nava, \& Ramos Cassellis, 2009).

El proceso se realizó en diferentes etapas en las que primeramente se extrajo la quitina y posteriormente se obtuvo el quitosano. Se empleó el método químico, donde se utilizaron soluciones de $\mathrm{HCl}$ y $\mathrm{NaOH}$ con la finalidad de remover lípidos, minerales, pigmentos y proteínas unidos a la quitina.

El rendimiento global del proceso de extracción del quitosano en los exoesqueletos, fue obtenido utilizando la siguiente expresión:

$$
\mathrm{RG}=\frac{R R}{R T} X 100
$$

Dónde:

RR: rendimiento real, cantidad en gramos del producto final (quitosano).

RT: rendimiento teórico, cantidad en gramos de la muestra con la que se comenzó el proceso.

Las concentraciones de quitosano empleadas en los tratamientos fueron 50 y $100 \%$.

\section{Preparación del ácido indol butírico}

Se utilizó un producto comercial sólido con un contenido de $80 \%$ de AIB. Se preparó el AIB colocando 0.937 y $1.25 \mathrm{~g}$, respectivamente, en $1 \mathrm{Kg}$ de talco agrícola inerte e inodoro, posteriormente, fue mezclado con una batidora doméstica para proceder a tratar los esquejes. Dichas concentraciones fueron seleccionadas de acuerdo a resultados óptimos obtenidos con AIB en estudios anteriores con especies leñosas (Cueva Solis, 2007; Panduro, Reátegui, Flores, \& Sánchez, 2017; Rivero, Guerrero, \& Ramírez, 2005).

\section{Tratamiento de los esquejes}

Se utilizó un diseño completamente al azar con nueve tratamientos los cuales pueden ser apreciados en la tabla 1; cada tratamiento contuvo 12 repeticiones. Se emplearon Esquejes de Salicornia bigelovii obtenidos de tallos de plantas madre recolectadas de la Bahía de Kino Sonora. Se realizó un corte en forma de cruz en la base de cada esqueje y fue sumergido en cada tratamiento a base de quitosano y/o AIB por 15 min.

Tabla 1. Tratamientos a base de bioproducto quitosano de origen marino (QUI) y Acido indol butírico (AIB).

\begin{tabular}{l}
\hline \multicolumn{1}{c}{ Tratamientos } \\
\hline Testigo (agua de riego potable) \\
QUI 50\% \\
QUI 100\% \\
AIB $0.937 \mathrm{~g} \mathrm{~kg}^{-1}$ \\
AIB $1.25 \mathrm{~g} \mathrm{~kg}^{-1}$ \\
QUI $50 \%+$ AIB $0.937 \mathrm{~g} \mathrm{~kg}^{-1}$ \\
QUI $50 \%+$ AIB $1.25 \mathrm{~g} \mathrm{~kg}^{-1}$ \\
QUI $100 \%+$ AIB $0.937 \mathrm{~g} \mathrm{~kg}^{-1}$ \\
QUI $100 \%+$ AIB $1.25 \mathrm{~g} \mathrm{~kg}^{-1}$ \\
\hline
\end{tabular}




\section{Trasplante de esquejes en microcuencas}

Esquejes de Salicornia bigelovii obtenidos de plantas de la Bahía de Kino Sonora fueron sometidos durante 30 días a un enraizamiento mediante tratamientos con quitosano y AIB (tabla 1) bajo condiciones de vivero (>90\% HR y a $27 \pm 2{ }^{\circ} \mathrm{C}$ ). Posteriormente al enraizado fueron tratados nuevamente y seguido se clavaron en las microcuencas bajo condiciones de campo $(<30 \%$ HR y a 47 $\pm 2{ }^{\circ} \mathrm{C}$ ). Se emplearon microcuencas de $7 \mathrm{~m}$ de largo y $1.5 \mathrm{~m}$ de ancho; los esquejes fueron ubicados a una distancia aproximada de $0.27 \mathrm{~m}$ entre esquejes, arrojando un total de 114 unidades experimentales. Previo al trasplante, se realizó un análisis al sustrato para determinar el contenido de materia orgánica (MO), macro- y micronutrientes, así como, el pH del suelo (tabla 2).

Tabla 2. Parámetros físicos y químicos del sustrato en las microcuencas experimentales en la costa de Hermosillo.

\begin{tabular}{lcccccccccc}
\hline Textura & $\mathbf{p H}$ & $\begin{array}{c}\mathrm{CE} \\
\mathbf{d S} / \mathbf{m}^{-1}\end{array}$ & $\begin{array}{c}\mathrm{M.O} \\
\mathbf{\%}\end{array}$ & $\mathbf{R A S}$ & $\begin{array}{c}\mathrm{NO}_{3} \\
\mathbf{m g} / \mathbf{K g}^{-1}\end{array}$ & $\begin{array}{c}\mathbf{N O}_{2} \\
\mathbf{m g} / \mathbf{K g}^{-1}\end{array}$ & $\begin{array}{c}\mathbf{C a} \\
\mathbf{m g} / \mathbf{K g}^{-1}\end{array}$ & $\begin{array}{c}\mathbf{M g} \\
\mathbf{m g} / \mathbf{K g}^{-1}\end{array}$ & $\begin{array}{c}\mathbf{K} \\
\mathbf{g} / \mathbf{L}^{-1}\end{array}$ & $\begin{array}{c}\mathbf{N a} \\
\mathbf{g} / \mathbf{L}^{-1}\end{array}$ \\
\hline Arenoso/limoso & 7.04 & 2.5 & 0.02 & 8.82 & 0.09 & 0.01 & 5.80 & 19.36 & 0.1 & 1.6 \\
\hline
\end{tabular}

El riego utilizado en una primera etapa (durante los 30 días después del trasplante (ddt), fue el de anegamiento diario $\left(47 \mathrm{~L} \cdot \mathrm{m}^{2}\right.$ ). Posteriormente, riegos alternados (cada tercer día), mediante un sistema de micro-aspersión fue utilizado durante 150 días después del anegamiento (dda).

\section{Peso seco, peso fresco y longitud radicular}

El peso fresco de la raíz se obtuvo después de cortar la parte aérea de los esquejes a partir de la base del tallo. El peso seco se alcanzó después de deshidratar las raíces a $80{ }^{\circ} \mathrm{C}$ en una estufa (Shel Lab modelo $1380 \mathrm{FM}$ ) durante $36 \mathrm{~h}$. La variable de longitud final radicular fue medida apoyándose con el uso de un vernier y regla milimétrica al cabo de $180 \mathrm{ddt}$.

\section{Altura final, porcentaje y aparición de floración y nitratos en savia}

Durante todo el ciclo fenológico de las plantas, se seleccionaron 10 de ellas al azar con la finalidad de medir su altura mensualmente. La altura de la planta fue considerada a partir de la base del tallo (cuello) hasta el ápice de la misma.

La aparición y el porcentaje de floración se evaluaron cuantificando cada 10 días las plantas en estado de floración, considerando la fecha de floración cuando el 50\% de las plantas se encontraban floreando.

Una vez presentada la etapa de floración en las plantas, se determinó el contenido de nitratos en savia

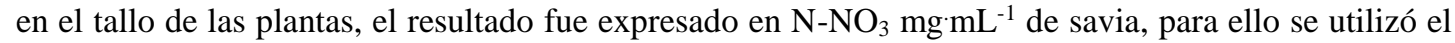
método de (Coombs, Hall, \& Long, 1988) y analizado según (Wood, Armstrong, \& Richards, 1967).

\section{Análisis proximal del tallo, raíz y fracción aérea de Salicornia bigelovii}

Se realizó un análisis bromatológico, donde se seleccionaron cinco plantas al azar y se tomaron por separado la raíz, el tallo y la fracción aérea; a estas regiones vegetales se les midieron: ceniza, lípidos, carbohidratos y proteínas. La técnica para obtener proteínas se desarrolló por el método de microKjeldahl; para carbohidratos se utilizó el método de (Dubois, Gilles, Hamilton, Rebers, \& Smith, 1956), mientras que el análisis de cenizas se realizó por diferencia de peso, calcinando la muestra a $500{ }^{\circ} \mathrm{C}$ por $24 \mathrm{~h}$, por último el análisis de lípidos totales se desarrolló empleando la técnica de (Barnes \& Blackstock, 1973).

\section{Análisis estadístico}

Se realizó un análisis de varianza de una sola vía y la separación de medias de las variables respuesta se realizó mediante la prueba de Rangos Múltiples de Tukey al 0.05\%. Los datos fueron analizados utilizando el programa estadístico de cómputo SAS ("Statistical Analysis System,” 2001). 


\section{RESUltados}

\section{Rendimientos de extracción de quitosano a partir de exoesqueletos de camarón}

De acuerdo a la metodología anteriormente planteada para la extracción de quitosano, se inició con $154.63 \mathrm{~g}$ de muestra de exoesqueletos de camarón del cual después de realizado el proceso se obtuvo $81.22 \mathrm{~g}$ de quitosano seco como producto final. Los resultados obtenidos muestran que el rendimiento de quitosano (según la ecuación 1 descrita con anterioridad) fue de $52.5 \%$.

\section{Peso fresco y seco en planta y longitud radicular}

Los resultados con relación a la variable de peso fresco de planta completa, los resultados arrojaron que el tratamiento que mostró resultados significativos $(\mathrm{P}<0.05)$, fue la mezcla de Quitosano (QUI) al $100 \%$ + AIB, en comparación de aquellos tratamientos utilizados de manera individual y del tratamiento testigo (tabla 3); numéricamente se puede apreciar que Quitosano $100 \%+$ AIB a razón de $0.937 \mathrm{~g} \mathrm{~kg}^{-1}$, se comporta superior de la concentración de $1.25 \mathrm{~g} \mathrm{~kg}^{-1}$ de AIB + Quitosano 100\%. Los tratamientos a base de Quitosano + AIB, son superiores hasta en un 35\% más de aquellos tratamientos donde los productos fueron evaluados de manera individual y hasta en un $80 \%$ superior del testigo control en la variable de peso fresco.

Un comportamiento similar fue el observado en los valores de peso seco de planta completa, pero con la diferencia que de aquellos tratamientos a base de Quitosano 100\% con AIB en las dos concentraciones evaluadas, sí mostraron diferencias significativas con $\mathrm{P}<0.05$. Por su parte en el peso seco, Quitosano $100 \%$ + AIB a razón de $0.937 \mathrm{~g} \mathrm{~kg}^{-1}$, supera en un 20,40 y $350 \%$ más, a los tratamientos donde se incorporan ambos productos (QUI+AIB) en otras concentraciones, de manera individual y el testigo control, respectivamente.

El mayor resultado con $\mathrm{P}<0.05$, con relación a la longitud radicular se obtuvo con las mezclas de Quitosano al $100 \%$ + AIB en ambas concentraciones estudiadas (0.937 y $\left.1.25 \mathrm{~g} \mathrm{~kg}^{-1}\right)$; se puede observar que la mezcla QUI $100 \%$ + AIB, superó en un 25,50 y $116 \%$ en la longitud radicular a los tratamientos donde se incorporan ambos productos (QUI+AIB) en otras concentraciones, de manera individual y el testigo control, respectivamente (tabla 3 ).

Tabla 3. Peso fresco, peso seco y longitud radicular durante el desarrollo vegetativo de Salicornia bigelovii tratadas con quitosano- AIB bajo condiciones de campo en la Costa de Hermosillo.

\begin{tabular}{|c|c|c|c|}
\hline Tratamientos & $\begin{array}{c}\text { Peso fresco } \\
\text { (g/planta) }\end{array}$ & $\begin{array}{l}\text { Peso seco } \\
\text { (g/planta) }\end{array}$ & $\begin{array}{c}\text { Longitud radicular } \\
(\mathrm{cm})\end{array}$ \\
\hline Testigo & $1382 \pm 4 d$ & $265 \pm 2 \mathrm{e}$ & $12 \pm 4 \mathrm{e}$ \\
\hline QUI $50 \%$ & $1779 \pm 3 c$ & $673 \pm 3 d$ & $12.5 \pm 5 \mathrm{e}$ \\
\hline QUI $100 \%$ & $1876 \pm 4 b$ & $654 \pm 3 d$ & $14 \pm 3 d$ \\
\hline AIB $0.937 \mathrm{~g} \mathrm{~kg}^{-1}$ & $1854 \pm 4 b$ & $597 \pm 5 d$ & $16 \pm 4 c$ \\
\hline AIB $1.25 \mathrm{~g} \mathrm{~kg}^{-1}$ & $1772 \pm 5 c$ & $672 \pm 2 d$ & $14 \pm 4 d$ \\
\hline QUI $50 \%+$ AIB $0.937 \mathrm{~g} \mathrm{~kg}^{-1}$ & $1898 \pm 2 b$ & $813 \pm 3 b$ & $17 \pm 4 c$ \\
\hline QUI $50 \%+$ AIB $1.25 \mathrm{~g} \mathrm{~kg}^{-1}$ & $1827 \pm 3 b$ & $729 \pm 3 c$ & $19 \pm 4 b$ \\
\hline QUI $100 \%+$ AIB $0.937 \mathrm{~g} \mathrm{~kg}^{-1}$ & $2652 \pm 4^{a}$ & $976 \pm 5^{a}$ & $26 \pm 5 a$ \\
\hline QUI $100 \%+$ AIB $1.25 \mathrm{~g} \mathrm{~kg}^{-1}$ & $2455 \pm 2^{a}$ & $789 \pm 4 c$ & $25 \pm 3 a$ \\
\hline
\end{tabular}

QUI: bioproducto quitosano de origen marino. AIB: Acido indol butírico. La media corresponde a cinco repeticiones de cada tratamiento. Las literales indican diferencia significativa con $p<0.05 \%$. 


\begin{abstract}
Altura final, Porcentaje y aparición de floración y Nitratos en Savia
Los resultados obtenidos muestran diferencias significativas $(\mathrm{P}<0.05)$ en altura final, resultando el más eficiente la mezcla de Quitosano $100 \%$ + AIB $0.937 \mathrm{~g} \mathrm{~kg}^{-1}$, seguido de Quitosano $100 \%$ - AIB $1.25 \mathrm{~g} \mathrm{~kg}^{-1}$. Se puede apreciar en la tabla 4 , que el tratamiento superior y previamente indicado, superó por arriba de un 50\% al testigo control, mientras que con aquellos donde se estudiaron al QUI y el AIB de manera separada, los superó por arriba de un $15 \%$.
\end{abstract}

Un similar comportamiento, fue observado en el porcentaje final de floración; los análisis estadísticos arrojaron diferencias significativas entre tratamientos ( $\mathrm{P}<0.05$ ) (tabla 4$)$, donde los valores altos son observados en el tratamiento con QUI $100 \%+$ AIB $0.937 \mathrm{~g} \mathrm{~kg}^{-1}$, resultando el tratamiento testigo el que arrojó los valores numéricos más bajos (15\% menos). Sin embargo, es importante hacer notar que, no obstante, los tratamientos a base de mezclas y de manera individual a base de quitosano y el AIB mostraron los valores altos en \% de floración, el testigo control inició su periodo de floración 13 días previos que lo iniciaran los demás tratamientos.

De igual forma, los valores de la variable nitratos, se comportaron inversamente proporcional, como se han estado describiendo en las previas variables (con excepción de \% final de floración); se puede observar que el mayor contenido se aprecia en el testigo con $1.7 \mathrm{NO}_{3} \mathrm{mg} \cdot \mathrm{mL}$ en savia, mientras que los valores más bajos fueron en aquellos tratamientos de QUI $50 \%$, AIB $0.937 \mathrm{~g} \mathrm{~kg}^{-1}$, QUI $50 \%$ + AIB $0.937 \mathrm{~g} \mathrm{~kg}^{-1}$ y QUI $50 \%$ + AIB $1.25 \mathrm{~g} \mathrm{~kg}^{-1}$.

Tabla 4. Dinámica de altura, porcentaje de floración y Nitratos en savia durante el desarrollo vegetativo de Salicornia bigelovii tratadas con quitosano-AIB bajo condiciones de campo en la Costa de Hermosillo.

\begin{tabular}{lccc}
\hline \multicolumn{1}{c}{ Tratamientos } & Altura $(\mathbf{c m})$ & Floración $(\%)$ & NO3 mg mL en savia \\
\hline Testigo & $28.7 \pm 4 \mathrm{e}$ & $65 \pm 3 \mathrm{e}$ & $1.7 \pm 0.02 \mathrm{a}$ \\
\hline QUI $50 \%$ & $36.5 \pm 5 \mathrm{~d}$ & $73 \pm 2 \mathrm{~d}$ & $0.7 \pm 0.03 \mathrm{c}$ \\
\hline QUI $100 \%$ & $37.2 \pm 2 \mathrm{~d}$ & $70 \pm 4 \mathrm{~d}$ & $1.01 \pm 0.04 \mathrm{~b}$ \\
\hline AIB $0.937 \mathrm{~g} \mathrm{~kg}^{-1}$ & $37.3 \pm 4 \mathrm{~d}$ & $71 \pm 3 \mathrm{~d}$ & $0.7 \pm 0.02 \mathrm{c}$ \\
\hline AIB $1.25 \mathrm{~g} \mathrm{~kg}^{-1}$ & $37.8 \pm 4 \mathrm{~d}$ & $72 \pm 2 \mathrm{~d}$ & $0.9 \pm 0.03 \mathrm{~b}$ \\
\hline QUI $50 \%+$ AIB $0.937 \mathrm{~g} \mathrm{~kg}^{-1}$ & $39.0 \pm 3 \mathrm{c}$ & $78 \pm 3 \mathrm{c}$ & $0.7 \pm 0.02 \mathrm{c}$ \\
\hline QUI $50 \%+$ AIB $1.25 \mathrm{~g} \mathrm{~kg}^{-1}$ & $40.5 \pm 3 \mathrm{~b}$ & $76 \pm 4 \mathrm{c}$ & $0.6 \pm 0.03 \mathrm{c}$ \\
\hline QUI $100 \%+$ AIB $0.937 \mathrm{~g} \mathrm{~kg}^{-1}$ & $43.8 \pm 4 \mathrm{a}$ & $90 \pm 3 \mathrm{a}$ & $1.2 \pm 0.04 \mathrm{~b}$ \\
\hline QUI $100 \%+$ AIB $1.25 \mathrm{~g} \mathrm{~kg}^{-1}$ & $41.5 \pm 3 \mathrm{~b}$ & $81 \pm 3 \mathrm{~b}$ & $0.6 \pm 0.02 \mathrm{c}$
\end{tabular}

QUI: bioproducto quitosano de origen marino. AIB: Acido indol butírico. La media corresponde a cinco repeticiones de cada tratamiento. Las literales indican diferencia significativa con $p<0.05 \%$.

Análisis proximal del tallo, raíz y fracción aérea de Salicornia bigelovii tratadas con quitosano-AIB El análisis proximal de las regiones evaluadas en el presente estudio mostró que los esquejes tratados con Quitosano-AIB, presentaron en raíz, tallo y fracción aérea, el mayor contenido de proteína, cenizas, lípidos y carbohidratos con relación al testigo. Los resultados presentaron diferencias significativas $(P<0.5)$ entre los tratamientos evaluados (tabla 5). En las tres regiones vegetales evaluadas se logró observar el predominio del tratamiento Quitosano $100 \%$ - AIB $0.937 \mathrm{~g} \mathrm{~kg}^{-1}$ en un $15 \%$ superior a los demás tratamientos, específicamente en proteína y en comparación del tratamiento 
testigo. Asimismo, se puede apreciar que los valores altos se aprecian en fracción aérea en comparación de tallo y raíz.

\section{DISCUSIÓN}

\section{Rendimiento de obtención de quitosano a partir de exoesqueletos de camarón}

El proceso de extracción del presente estudio permitió obtener un porcentaje en rendimiento de 52.5\%; estudios relacionados con la extracción indican que los rendimientos pueden variar entre las especies marinas, donde las mayores producciones de quitina y quitosano, en porcentaje, se obtienen a partir de caparazones y residuos de diversas especies de cangrejo, que alcanzan niveles de 64,2 a 72,1\%, mientras que para camarones alcanza niveles de 69,1\% (Isique Calderón, Morales, Quispe., \& Quispe, 2017). Asimismo, el rendimiento en quitina y quitosano de exosqueletos de crustáceos depende de la materia prima y de los ajustes del método utilizado (Covas, 2006; Hernández Cocoletzi et al., 2009), donde el quitosano ha llegado a representar hasta un 76,8\% de la quitina de las especies (Covas, 2006; Mármol, Gutiérrez, Páez, Ferrer, \& Rincón, 2004).

\section{Peso fresco y peso seco y longitud radicular}

Los resultados obtenidos en las variables de peso fresco y peso seco a los 180 días ddt, mostraron incrementos significativos, sobresaliendo el tratamiento de Quitosano 100\%-AIB $0.937 \mathrm{~g} \mathrm{~kg}^{-1}$ (tabla 3), lo anterior muestra que el quitosano mejora considerablemente la producción de biomasa en la Salicornia bigelovii. El presente estudio es el primer reporte de los efectos de quitosano en la halófita Salicornia bigelovii. Estudios en Salicornia como el realizado por (Rueda-Puente, Castellanos, TroyoDiéguez, Díaz De León-Alvarez, \& Murillo-Amador, 2003) indican un incremento significativo en peso fresco y peso seco al emplear bacterias promotoras del crecimiento vegetal (BPCV) tales como Klebsiella pneumonie y Azospirillum halopraeferens. Así mismo, (Villegas Espinoza et al., 2010) y (Hernández Perales et al., 2016), reportan un incremento en dichas variables utilizando microorganismos benéficos. En otros cultivos, estudios como el de (El-Miniawy, Ragab, Youssef, \& Metwally, 2013) en plantas de fresa tratadas con quitosano, han mostrado incremento significativo en el peso fresco y peso seco así como en otras variables de desarrollo vegetal como longitud de la planta, número de hojas/planta, área foliar y crecimiento radicular. Se ha mencionado que el quitosano estimula el metabolismo de las plantas de manera que mejora las características propias de las mismas. Lo anterior es posible gracias al mecanismo de fitoprotección donde actúa como elicitor y bioestimulante, fungistático, nematostático y protector de enfermedades aéreas, produciendo un efecto positivo en el crecimiento vegetal (Kessel Domini., 2018).

Gracias a las múltiples propiedades del quitosano en agricultura, actualmente se ha considerado como un bioplaguicida activador de los mecanismos de defensa de las plantas (Falcón Rodríguez, Costales, González, \& Nápoles, 2015), además de ser un producto aprobado por la EPA con número de referencia 128930.

En la variable de longitud radicular, los tratamientos mostraron diferencias significativas $(\mathrm{P}<0.05)$, sobresaliendo el tratamiento con Quitosano $100 \%$ - AIB $0.937 \mathrm{~g} \mathrm{~kg}^{-1}$. El quitosano en la Salicornia favorece el desarrollo de la raíz de la halófita, posiblemente al mecanismo de acción del quitosano en las plantas, donde este prevé un "falso efecto de estrés" que puede ser biótico o abiótico y activando los diferentes mecanismos de defensa de la planta; lo anterior permite una "expectativa" activa de la planta y generando un desarrollo radicular de la Salicornia y por ende reflejando un desarrollo vegetativo y más sano en toda la planta. El quitosano también activa la formación de barreras físicas, produciendo que el flujo de nutrientes no pase al patógeno, probablemente por la acumulación de sustancias fungitóxicas por parte del biopolímero (Lizárraga, Torres, Moreno, \& Miranda, 2011). Otras investigaciones han mostrado efecto benéfico por parte del quitosano en diferentes cultivos: arroz (Molina Zerpa et al., 2017), fresa (El-Miniawy et al., 2013), Alcachofa (Ziani, Ursúa, \& Maté, 2010), tomate (Peniche C., 2006).

En el estudio de (Molina Zerpa et al., 2017), se reportó un incremento de hasta 52\% en la raíz de plantas de arroz con respecto al testigo empleado, los autores concluyeron que dichos resultados se 
deben a la capacidad estimulante del quitosano, ya que actúa mejorando el enraizamiento y la producción del área foliar de la planta.

De igual manera, se ha discutido el efecto bioestimulante del quitosano en las semillas, donde se ha señalado que no solo aumenta el porcentaje de germinación sino también las plantas resultantes son más vigorosas, es decir presentan mayor crecimiento longitudinal y diámetro de vástago (Peniche C., 2006). Así mismo, autores como (Reddy, Arul, Angers, \& Couture, 1999) indican que el quitosano muestra efectos positivos en el crecimiento de las plantas (raíces, retoños y hojas), lo anterior gracias a la estructura molecular del polímero que, al entrar en contacto con la planta, activa mecanismos de defensa, produciendo aumentos significativos en el desarrollo de la raíz, una mejor absorción de nutrientes y mayor fuerza y vigor en estas (Molina Zerpa et al., 2017). El aumento en el desarrollo del sistema radicular así como el fortalecimiento y vigor también se ha relacionado al grado de lignificación de las plantas mediante el mecanismo Resistencia Sistémica Adquirida (RSA) (Benhamou, Lafontaine, \& Nicole, 1994), que es un mecanismo que le confiere protección a la planta ante infecciones secundarias por patógenos (Puentes, 2012). Aunado a lo anterior, el quitosano protege a las raíces ante situaciones de stress hídrico, ya sea por falta o exceso de agua, permitiendo un mejor y rápido crecimiento radicular de las plantas (El Ghaouth, Arul, Ponnampalam, \& Boulet, 1991).

Si bien, en Salicornia no se ha utilizado el quitosano como estimulante del desarrollo vegetal, el empleo de otros estimulantes como los microorganismos ha producido incremento en el crecimiento de la radícula (Rueda-Puente et al., 2003; Rueda Puente et al., 2009). En el presente estudio el efecto del quitosano se incrementó empleando el AIB, lo que sugiere que ambos compuestos se complementan de una forma sinérgica logrando una alta y doble eficacia.

\section{Altura final, Porcentaje y aparición de floración y Nitratos en Savia}

Los resultados obtenidos en la variable de altura en la etapa de floración mostraron diferencias significativas $(\mathrm{P}<0.05)$ entre los tratamientos utilizados, donde el tratamiento a base de Quitosano $100 \%$-AIB $0.937 \mathrm{~g} \mathrm{~kg}^{-1}$ incrementaron hasta en un $50 \%$ más, la variable de altura en la halófita. En Salicornia bigelovii se ha obtenido incremento en la altura de las plantas mediante la utilización de algunos compuestos con capacidad biofertilizante, tal es el caso de algunas bacterias promotoras de crecimiento (Hernández Perales et al., 2016; Rueda Puente et al., 2009; Villegas Espinoza et al., 2010), donde se ha indicado que hormonas como las auxinas, citocininas y giberelinas, exhiben propiedades fuertes de regulación del crecimiento (Bashan et al., 2000; Lira Saldivar, 2003; Rueda Puente et al., 2009). Nuestros resultados sugieren que el quitosano en sinergia con el AIB estimula la producción de este tipo de fitohormonas que terminan por favorecer el desarrollo general de la planta.

Por otra parte, en plantas de Arroz tratadas con quitosano, la altura de las mismas se incrementó en un $16.5 \%$ en comparación con el testigo. En dicho estudio se concluyó que el cultivo de arroz presentó un mejor desarrollo vegetativo con el tratamiento con quitosano (Molina Zerpa et al., 2017). Así mismo, en frijol ( $P$. vulgaris) (Sheikha \& Al-Malki, 2011), se encontraron resultados favorables en el crecimiento de los tallos de las plantas tratadas con quitosano. Otros estudios han mostrado resultados óptimos en la variable de altura de las plantas al emplear quitosano como tratamiento bioestimulante (Cebreros, Valle, Peña, Feria, \& Ramírez, 2018; Morales, Dell'Amico, Jerez, Díaz, \& Martín, 2016).

Los resultados obtenidos con respecto al porcentaje de floración mostraron diferencias significativas entre tratamientos $(\mathrm{P}<0.05)$. En Salicornia bigelovii se ha conseguido incrementar el porcentaje de floración mediante la utilización de bacterias promotoras de crecimiento (Rueda-Puente et al., 2003), lo anterior sugiere que dichas bacterias, en general, pueden contribuir al crecimiento y aumento del rendimiento de muchos cultivos agrícolas importantes (Puente, Li, \& Bashan, 2004) gracias a la interacción planta-microorganismo. En el caso del quitosano, en el presente estudio mostró un efecto benéfico; en otros cultivos el quitosano ha logrado aumentar el porcentaje de floración de diferentes plantas como la habichuela (Cebreros et al., 2018), frijol (Mondal, Puteh, \& Dafader, 2016), orquídea (Sopalun., Thammasiri., \& Ishikawa., 2010).

Se ha mencionado que el quitosano cuando es aplicado en la etapa inicial de floración en los cultivos, estimula el crecimiento en tallos, hojas y tamaño de los frutos, aumentado los rendimientos 
agronómicos de los cultivos al compararlos con las plantas donde no es utilizado (Molina, 2015). Por otra parte, en otros cultivos como la planta de pimiento (Capsicum annuum) la aplicación foliar con quitosano ha mostrado la habilidad de reducir la transpiración aumentando el uso eficiente del agua, a través del cierre parcial o total de los estomas (Bittelli, Flury, Campbell, \& Nichols, 2001). Lo anterior sugiere que el quitosano mejora la producción de flor, considerando variables agrometeorológicas como la disponibilidad hídrica en el suelo, la temperatura del aire y el brillo solar (Camayo Vélez, Chaves Córdoba, Arcila Pulgarín, \& Jaramillo Robledo, 2003). En este sentido, el efecto benéfico de los biofertilizantes se atribuye a que la planta dispone de mayor cantidad de nutrientes y hace más eficiente el uso de recursos naturales como agua y radiación solar, esto permite a la planta tener una nutrición más adecuada y ser más resistente al ataque de plagas, como consecuencia la producción de flor y los rendimientos son mayores (Mejía, Álvarez, \& Luna, 2011). En estudios con café (Ramírez et al., 2010), se ha encontrado que la floración en dicha planta, es producto de la integración de varios estímulos ambientales como el déficit hídrico, la disponibilidad energética y los cambios diarios de temperatura. Lo anterior sugiere que, en el presente estudio las condiciones meteorológicas en que se desarrolló el estudio, fueron apropiadas para la estimulación del proceso de floración de Salicornia bigelovii el cual se mostró intensificado por efecto del quitosano. Los resultados obtenidos en el incremento del porcentaje de floración sugieren una mayor capacidad fotosintética lo cual se ve reflejado en el incremento de materia seca y en el rendimiento general de la halófita Salicornia bigelovii.

La savia es un fluido viscoso que tiene como función principal transportar los nutrientes en la planta, es el jugo extraído de los tejidos conductores que proviene tanto del xilema como del floema de la planta (Cadahia, 2008). Está conformada por agua, minerales, reguladores de crecimiento entre otras sustancias y es transportada desde la raíz hasta las hojas; su análisis nos permite identificar la concentración de los nutrientes en las diferentes fases fenológicas de la planta y su relación con su potencial de rendimiento (Cary, 1971; Fageria, Baligar, \& Jones, 1991) evidenciando la relación planta-suelo. En el presente estudio se obtuvo un menor contenido de Nitratos en savia en los tratamientos a base de quitosano y AIB en comparación del testigo utilizado (tabla 4), lo anterior se debe al aprovechamiento eficiente de nutrientes para producir biomasa; los resultados de esta investigación concuerdan con los de (Pérez Silva R., 1989), (Blackmer \& Schepers, 1995) en estudios de plantas de maíz (Zea mays). Así mismo se ha investigado e informado la disminución de nitratos y la conversión a formas proteicas por (Goffart, Olivier, \& Frankinet, 2008; Kolbe \& Stephan Beckmann, 1997; Ruza, Skrabule, \& Vaivode, 2013).

(Rueda-Puente et al., 2003) en Salicornia bigelovii reportó que los contenidos de nitratos en savia en las plantas tratadas con bacterias fijadoras de nitrógeno fueron menores que en las plantas no tratadas, sugiriendo que los nitratos en la savia de las plantas están siendo dirigidos a la formación de biomasa. Por otra parte, en otros cultivos como la papa (González Gómez et al., 2017), se ha relacionado la concentración de nitratos en savia con la etapa vegetativa, demostrando efectos benéficos en el desarrollo de la misma, re-dirigiéndola a producción de biomasa.

\section{Análisis proximal del tallo, raíz y fracción aérea de Salicornia bigelovii}

Los resultados del análisis proximal presentaron diferencias significativas $(\mathrm{P}<0.5)$ entre los tratamientos evaluados, donde en las tres regiones vegetales evaluadas se logró observar un comportamiento similar, sobresaliendo el tratamiento Quitosano 100\% - AIB 0.937 g kg-1. 


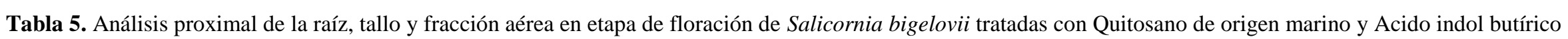
(AIB) bajo condiciones de campo en la Costa de Hermosillo.

\begin{tabular}{|c|c|c|c|c|c|c|c|c|c|c|c|c|}
\hline Región & \multicolumn{4}{|c|}{ Raíz } & \multicolumn{4}{|c|}{ Tallo } & \multicolumn{4}{|c|}{ Fracción aérea } \\
\hline Variables (\%) & Pro & Cen & Líp & CHO & Pro & Cen & Líp & CHO & Pro & Cen & Líp & CHO \\
\hline Testigo & $6.11 \mathrm{c}$ & $32.45 \mathrm{c}$ & $53.2 \mathrm{e}$ & $30.97 d$ & $7.40 \mathrm{e}$ & $40.12 \mathrm{c}$ & $16.24 \mathrm{e}$ & $39.78 \mathrm{e}$ & $9.10 \mathrm{c}$ & $58.62 \mathrm{c}$ & $23.96 \mathrm{c}$ & $46.25 \mathrm{e}$ \\
\hline QUI 50\% & $6.42 \mathrm{~b}$ & $35.77 \mathrm{~b}$ & $78.4 \mathrm{~d}$ & $38.90 \mathrm{~b}$ & $8.49 \mathrm{~d}$ & $41.56 \mathrm{c}$ & $17.20 \mathrm{~d}$ & $41.87 \mathrm{~d}$ & $9.75 \mathrm{c}$ & $57.93 \mathrm{c}$ & $25.00 \mathrm{~b}$ & $54.17 \mathrm{c}$ \\
\hline QUI $100 \%$ & $7.58 \mathrm{a}$ & $36.23 \mathrm{~b}$ & $96.8 \mathrm{~b}$ & $39.50 \mathrm{~b}$ & $11.80^{\mathrm{a}}$ & $43.52 \mathrm{~b}$ & $28.73 a$ & $42.53 \mathrm{c}$ & $11.38 \mathrm{~b}$ & $61.19 \mathrm{a}$ & $29.37 \mathrm{a}$ & $55.30 \mathrm{~b}$ \\
\hline AIB $0.937 \mathrm{~g} \mathrm{~kg}^{-1}$ & $7.43 \mathrm{a}$ & $31.45 \mathrm{c}$ & $79.5 \mathrm{~d}$ & $37.10 \mathrm{c}$ & $9.50 \mathrm{c}$ & $42.96 \mathrm{c}$ & $18.21 \mathrm{c}$ & $41.70 \mathrm{~d}$ & $9.77 \mathrm{c}$ & $58.74 \mathrm{c}$ & $26.00 \mathrm{~b}$ & $52.13 c$ \\
\hline AIB $1.25 \mathrm{~g} \mathrm{~kg}^{-1}$ & $7.25 \mathrm{a}$ & $31.65 \mathrm{c}$ & $91.6 \mathrm{c}$ & $37.74 \mathrm{c}$ & $10.89 \mathrm{~b}$ & $42.49 \mathrm{cb}$ & $26.35 b$ & $43.80 \mathrm{c}$ & $11.49 \mathrm{~b}$ & $60.00 \mathrm{~b}$ & $28.74 a$ & $52.89 c$ \\
\hline QUI 50\% + AIB $0.937 \mathrm{~g} \mathrm{~kg}^{-1}$ & $7.57 \mathrm{a}$ & $35.56 \mathrm{~b}$ & $96.8 \mathrm{~b}$ & $37.65 c$ & $11.78 \mathrm{a}$ & $43.49 \mathrm{~b}$ & $28.71 \mathrm{a}$ & $44.50 \mathrm{c}$ & $11.40 \mathrm{~b}$ & $61.20 \mathrm{a}$ & $29.96 \mathrm{a}$ & $56.89 \mathrm{~b}$ \\
\hline QUI $50 \%+$ AIB $1.25 \mathrm{~g} \mathrm{~kg}^{-1}$ & $6.81 \mathrm{~b}$ & $35.23 b$ & $97.6 \mathrm{~b}$ & $37.67 \mathrm{c}$ & $9.59 \mathrm{c}$ & $44.58 \mathrm{~b}$ & $19.52 \mathrm{c}$ & $41.34 d$ & $8.25 \mathrm{~d}$ & $60.18 b$ & $24.56 \mathrm{c}$ & $55.83 \mathrm{~b}$ \\
\hline QUI $100 \%+$ AIB $0.937 \mathrm{~g} \mathrm{~kg}^{-1}$ & $7.79 \mathrm{a}$ & $39.35 \mathrm{a}$ & $100.3 \mathrm{a}$ & $41.35 \mathrm{a}$ & $11.77^{\mathrm{a}}$ & $47.29 \mathrm{a}$ & $25.86 \mathrm{~b}$ & $48.67 \mathrm{a}$ & $12.76 \mathrm{a}$ & $61.86 \mathrm{a}$ & $30.73 \mathrm{a}$ & $58.60 a$ \\
\hline QUI $100 \%+$ AIB $1.25 \mathrm{~g} \mathrm{~kg}^{-1}$ & $6.45 b$ & $38.46 a$ & $78.4 \mathrm{~d}$ & $39.80 \mathrm{~b}$ & $8.49 \mathrm{~d}$ & $41.95 \mathrm{c}$ & $17.20 \mathrm{~d}$ & $46.34 b$ & $9.75 \mathrm{c}$ & $57.83 \mathrm{c}$ & $25.10 \mathrm{~b}$ & $58.10 a$ \\
\hline
\end{tabular}

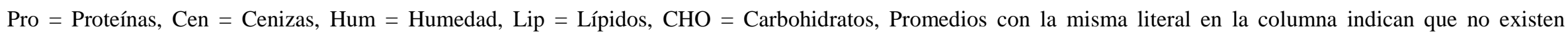
diferencias significativas $(\mathrm{P}>0.05)$. 
Los resultados del análisis proximal, evidenciaron el alto contenido de cenizas en tallo y fracción área en comparación con raíz; los resultados obtenidos en las variables evaluadas coinciden con autores como (Karlova \& de Vries, 2006), quienes indican que los compuestos bioestimulantes son capaces de estimular e incrementar los valores bromatológicos debido al crecimiento de tallos, hojas, frutos, además de incrementar rendimiento del cultivo comparado con las plantas donde no son aplicados. Por otra parte, (Imamul Huq. \& Larher., 1983, 1984), indican que en halófitas el incremento de bioproductos a nivel celular, se relaciona con el proceso de osmoregulación, donde es necesario que un sistema contiguo sea más concentrado del otro. Es decir, para que el agua viaje de la raíz hasta el ápice se requiere que las partes aéreas estén más concentradas en solutos que la raíz de la planta; ocasionalmente las altas cantidades de solutos en las halófitas son carbohidratos y proteínas que actúan como osmoprotectantes y reguladores, lo anterior concuerda con los resultados obtenidos en nuestro estudio donde se puede apreciar valores altos en la parte aérea en comparación de tallo y raíz.

Salicornia bigelovii es una halófita rica en proteínas y carbohidratos mismos que pueden ser aprovechados para la alimentación humana y animal, para fines médicos, fitorremediación entre otros (Attia, FM., Alsobayel, A. A., Kriadees, M. S., Al-Saiady, M. Y. \& Bayoumi, 1997; Belal \& AlDosari, 1999; E. P. Glenn et al., 2012; Kim, 2017; Kraidees, Abouheif, Al-Saiady, Tag-Eldin, \& Metwally, 1998; Lim et al., 2017; Manousaki \& Kalogerakis, 2011; Slama, Abdelly, Bouchereau, Flowers, \& Savouré, 2015; Ventura et al., 2011; Warshay, Pan, \& Sgouridis, 2011). El contenido de proteína, fibra y cenizas totales por hectárea se ha reportado entre los 30-40\%, 4.5-8\% y $5.5-8.5 \%$ respectivamente (Anwar, Bhanger, Nasir, \& Ismail, 2002; Burboa et al., 2017; E. Glenn, O'leary, Watson, Thompson, \& Kuehl, 1991; Gunstone, Harwood, \& Dijkstra, 2007).

Con relación a carbohidratos se ha reportado que Salicornia bigelovii contiene una gran cantidad de estos (Bañuelos, JA, Velázquez, I., Guerra, M. \& Arjona, 2018; Cybulska et al., 2014), entre los que destacan la hemicelulosa y celulosa, esta última en cantidades elevadas, lo anterior hace que está halófita sea propuesta como una fuente importante en la industria sobre todo para la de los biocombustibles donde puede ser utilizada para la producción de bioetanol (Bañuelos, JA, Velázquez, I., Guerra, M. \& Arjona, 2018). Por otra parte, (Cybulska et al., 2014), encontraron en muestras cultivadas en emiratos árabes alrededor de $9.1 \mathrm{~g} /(100 \mathrm{~g}$ de muestra) de glucanos, 7,7 g/ (100 g muestra) de xilano, 5,5 $\pm 2,1 \mathrm{~g} /$ ( $100 \mathrm{~g}$ de muestra) de arabina y 1.9 - $6.8 \mathrm{~g} /$ ( $100 \mathrm{~g}$ de muestra) de lignina evaluados en materia seca.

Los resultados obtenidos en el presente estudio se deben a las propiedades estructurales del quitosano el cual está compuesto por dos unidades estructurales de N-acetil-D-glucosamina y la D-glucosamina (Peniche C., 2006), mismas que presentan un contenido de Nitrógeno (N) cerca del 7\% (Kumar, 2000; Muzzarelli, 1977) y durante el proceso de degradación del quitosano probablemente dicho nitrógeno fue aprovechado por la planta. Aunado a lo anterior, se ha reportado que después del proceso de desacetilación de la quitina, el quitosano resultante se convierte en una molécula policatiónica (Glasser, 1997), gracias a la distribución regular de los grupos aminos libres que posee en su estructura. Esta característica le permite al biopolímero interactuar activamente con diversas moléculas como lípidos, proteínas, pigmentos, entre otras (Rodríguez et al., 2009).

Los mecanismos de acción del quitosano no han sido completamente elucidados, sin embargo, la estructura química, su comportamiento policatiónico y las propiedades bioactivas del quitosano, lo convierten en un biopolímero con potenciales aplicaciones, mismas que pueden ser aprovechadas en distintos ámbitos industriales y científicos.

\section{CONCLUSIONES}

La halófita Salicornia bigelovii es un recurso vegetal con alto potencial de ser aprovechado en las zonas desérticas costeras del noroeste de México; sin embargo, su productividad depende de la aportación suplementaria de nitrógeno, así como de otros macro y micro nutrientes esenciales. En el presente estudio la aplicación del bioproducto quitosano de origen marino en sinergia con AIB, presento un efecto bioestimulador en las variables del desarrollo radicular y crecimiento de planta, 
además de características bioquímicas, incluyendo la proteína total, ceniza y lípidos totales en algunas partes de la planta.

Este es el primer informe de quitosano en Salicornia bigelovii, por lo que se recomienda desarrollar estudios con diferentes genotipos de Salicornia, bajo distintas condiciones salinas.

Finalmente, es importante mencionar que este trabajo contribuye a ampliar el conocimiento en las posibles alternativas de producción agrícola y efectos en el diseño y aplicación de biofertilizantes con potencial productivo de interés socio-económico, para estados con problemas de disponibilidad de agua, salinidad de suelos y bajos contenidos de materia orgánica como es Sonora y Baja California, en el Noroeste de México.

\section{AGRADECIMIENTOS}

Agradecemos a CONACYT por el apoyo en la Beca Nacional 332147 para el nivel de Doctorado en el Instituto Tecnológico de Sonora en Obregón, Sonora, México.

\section{LITERATURA CITADA}

Alvarado, J. de D., Almeida, A., Arancibia, M., García, A., Pinotti, A., \& Zaritzky, N. (2019). Obtención y caracterización de quitina y quitosano extraídos de exoesqueletos de camarón (Penaeus vannamei). Investigación y Desarrollo, 1(1), 58-80.

Anwar, F., Bhanger, M. I., Nasir, M. K. A., \& Ismail, S. (2002). Analytical characterization of Salicornia bigelovii seed oil cultivated in Pakistan. Journal of Agricultural and Food Chemistry, 50(15), 4210-4214. https://doi.org/10.1021/jf0114132

Attia, FM., Alsobayel, A. A., Kriadees, M. S., Al-Saiady, M. Y. \& Bayoumi, M. S. (1997). Nutrient composition and feeding value of Salicornia bigelovii torr meal in broiler diets. Animal Feed Science and Technology, 65(1-4), 257-263.

Bañuelos, JA, Velázquez, I., Guerra, M. \& Arjona, N. (2018). Production, characterization and evaluation of the energetic capability of bioethanol from Salicornia bigelovii as a renewable energy source. Renewable Energy, 123, 125-134.

Barnes, H., \& Blackstock, J. (1973). Estimation of lipids in marine animals and tissues: detailed investigation of the sulphophosphovanilun method for 'total'lipids. Journal of Experimental Marine Biology, 12(1), 103-118.

Bashan, Y., Puente, M. E., Salazar, B., De-Bashan, L. E., Bacilio, M., Hernandez, J.-P., ... Bethlenfalvay, G. J. (2000). LA MATERIA ORGÁNICA [Reforestation of eroded land in the desert. Role of plant growth promoting bacteria and organic matter]. In Suelos Ecuatoriales (Vol. 35).

Belal, I. E. H., \& Al-Dosari, M. (1999). Replacement of fish meal with salicornia meal in feeds for Nile tilapia Oreochromis niloticus. Journal of the World Aquaculture Society, 30(2), 285-289. https://doi.org/10.1111/j.1749-7345.1999.tb00877.x

Benhamou, N., Lafontaine, P., \& Nicole, M. (1994). Induction of systemic resistance to Fusarium crown and root rot in tomato plants by seed treatment with chitosan. Phytopathology, 84(12), $1432-1444$.

Bernadette Dima., J. (2014). Obtención de quitina y quitosano a partir de exoesqueletos de crustáceos patagónicos: caracterización y aplicaciones.

Bittelli, M., Flury, M., Campbell, G. S., \& Nichols, E. J. (2001). Reduction of transpiration through foliar application of chitosan. In Agricultural and Forest Meteorology (Vol. 107).

Blackmer, T. M., \& Schepers, J. S. (1995). Use of a Chlorophyll Meter to Monitor Nitrogen Status and Schedule Fertigation for Corn. In Journal of production agriculture (Vol. 8).

Burboa, C., M., A., O., B., G., A., J., V., L., H., \& R., A. (2017). Salicornia bigelovii (TORR.): UN SISTEMA MODELO PARA INCORPORARSE COMO CULTIVO AGRÍCOLA EN ZONAS ÁRIDO-DESÉRTICOS. Biotecnia, 19, 46-50. 
Cadahia, C. (2008). La savia como índice de fertilización. Madrid. Mundi-Prensa Libros.

Camayo Vélez, C., Chaves Córdoba, B., Arcila Pulgarín, J., \& Jaramillo Robledo, Á. (2003). Desarrollo floral del cafeto y su relación con las condiciones climaticas de Chinchina Caldas (Vol. 54).

Cary, P. (1971). Irrationality of using leaf analysis as a unique reference to citrus fertilizer requirement. Gordon and Breach Science Publishers, 1. New York, USA.

Cebreros, M., Valle, E., Peña, E., Feria, C., \& Ramírez, G. (2018). Respuesta agroproductiva de la habichuela (Vigna unguiculata (L) Walp.) a la aplicación simple y combinada de bioestimulantes y micorrizas en condiciones de organopónico en Cuba. Revista de La Facultad de Ciencias Agrarias., 48(2), 31-42.

Coombs, J., Hall, D., \& Long, S. (1988). Técnicas en fotosíntesis y bioproductividad. México. Ed. Futura.

Covas, C. A. (2006). Estudios sobre quitina y quitosano. Universidad de La Habana- Cuba.

Cueva Solis, S. (2007). Efecto del ácido indol-3-butírico (AIB) para incrementar la producción de raíces comerciales en yuca (Manihot esculenta) "Valencia."

Cybulska, I., Chaturvedi, T., Brudecki, G. P., Kádár, Z., Meyer, A. S., Baldwin, R. M., \& Thomsen, H. (2014). Chemical characterization and hydrothermal pretreatment of Salicornia bigelovii straw for enhanced enzymatic hydrolysis and bioethanol potential. Bioresource Technology, 153, 165-172. https://doi.org/10.1016/j.biortech.2013.11.071

Devlieghere, F., Vermeulen, A., \& Debevere, J. (2004). Chitosan: antimicrobial activity, interactions with food components and applicability as a coating on fruit and vegetables. Food Microbiology, 21(6), 703-714.

Dubois, M., Gilles, K. A., Hamilton, J. K., Rebers, P. A., \& Smith, F. (1956). Colorimetric Method for Determination of Sugars and Related Substances. Analytical Chemistry, 28(3), 350-356. https://doi.org/10.1021/ac60111a017

El-Miniawy, S., Ragab, M., Youssef, S., \& Metwally, A. (2013). Response of Strawberry Plants to Foliar Spraying of Chitosan ORIGINAL ARTICLES Response of Strawberry Plants to Foliar Spraying of Chitosan. Research Journal of Agriculture and Biological Sciences, 9(6), 366372 .

El Ghaouth, A., Arul, J., Ponnampalam, R., \& Boulet, M. (1991). Chitosan Coating Effect on Storability and Quality of Fresh Strawberries. Journal of Food Science, 56(6), 1618-1620. https://doi.org/10.1111/j.1365-2621.1991.tb08655.x

Fageria, N., Baligar, V., \& Jones, C. (1991). Growth ad mineral nutrition of field crops (Marcel Dekker Inc., Ed.). New York, USA.

Falcón Rodríguez, A., Costales, D., González, D., \& Nápoles, M. (2015). Nuevos productos naturales para la agricultura: las oligosacarinas. Cultivos Tropicales, 36, 11-129.

Gildberg, A., \& Stenberg, E. (2001). A new process for advanced utilisation of shrimp waste. Process Biochemistry, 36, 809-812.

Glasser, W. (1997). Preparation of $N$-acylglucosamine polymers from chitosan for chitin fibers and filaments. Canada Pat CA.

Glenn, E., O’leary, J., Watson, M., Thompson, T., \& Kuehl, R. (1991). Salicornia bigelovii Torr.: an oilseed halophyte for seawater irrigation. Science, 251(4997), 1065-1067.

Glenn, E. P., Anday, T., Chaturvedi, R., Martinez-Garcia, R., Pearlstein, S., Soliz, D., ... Felger, R. S. (2012). Three halophytes for saline-water agriculture: An oilseed, a forage and a grain crop. Environmental and Experimental Botany, 92, 110-121. https://doi.org/10.1016/j.envexpbot.2012.05.002

Goffart, J. P., Olivier, M., \& Frankinet, M. (2008). Potato crop nitrogen status assessment to improve $\mathrm{N}$ fertilization management and efficiency: Past-present-future. Potato Research, 51(3-4), 355-383. https://doi.org/10.1007/s11540-008-9118-x

González, A., \& Arbo, M. (2006). Botánica Morfológica. Morfología de las plantas vasculares. Facultad de Ciencias Agrarias, Universidad Nacional del Nordeste, Corrientes, Argentina. Universidad Nacional del Nordeste, Corrientes, Argentina.

González Gómez, L., M., J., L., V., I., P., A., F., \& L., A. (2017). Evaluación de la aplicación de quitosana sobre plántulas de tabaco (Nicotiana tabacum L.). Revista Centro Agrícola, 44(1), 34-40. 
Gunstone, F. D., Harwood, J. L., \& Dijkstra, A. J. (2007). The lipid handbook with CD-ROM (3rd ed.). Boca Raton, Florida.: CRC Press.

Hadwiger, L., Fristensky, B., \& Riggleman, R. (1984). Chitin, chitosan and related enzymes (J. P. F. Ed., Ed.). Orlando Florida: Academic Press Inc.

Hernández Cocoletzi, H., Águila Almanza, E., Flores Agustin, O., Viveros Nava, E., \& Ramos Cassellis, E. (2009). Obtención y caracterización de quitosano a partir de exoesqueletos de camarón. Superficies y Vacío, 22(3), 57-60.

Hernández Herrera, R., Santacruz, F., Briceño, D., Di Filippo, D., \& Hernández, G. (2018). Seaweeds as Potential Plant Growth Stimulants for Agriculture in Mexico. Hidrobiológica, 28(1), 129140. https://doi.org/10.24275/uam/izt/dcbs/hidro/2018v28n1/HernandezC

Hernández Perales, M., Cisneros, R., Ortega, J., Márquez, C., Reyes, J., Murillo, B., \& E., R. (2016). Mitigación del efecto de sales clorhídricas y sulfáticas en la germinación de Salicornia bigelovii (Torr.) por bacterias benéficas in vitro. Revista Mexicana de Ciencias Agrícolas, 7(4), 923-934.

Hewajulige, I., Sivakumar, D., Sultanbawa, Y., Wijesundera, R., \& S., W. R. (2007). Effect of chitosan coating on the control of anthracnose and overall quality retention of papaya (Carica papaya L.) during storage. Acta Horticulturae, 740, 245-250.

Imamul Huq., S., \& Larher., F. (1983). OSMOREGULATION IN HIGHER PLANTS: EFFECTS OF NaCl SALINITY ON NON-NODULATED PHASEOLUS AUREUS L. I. GROWTH AND MINERAL CONTENT. New Phytologist, 93(2), 203-208. https://doi.org/10.1111/j.14698137.1983.tb03424.X

Imamul Huq., S., \& Larher., F. (1984). Osmoregulation in higher plants: effects of maintaining a constant $\mathrm{Na}$ :Ca ratio on the growth, ion balance and organic solute status of $\mathrm{NaCl}$ stressed cowpea (Vigna sinensis L.). Zeitschrift Für Pflanzenphysiologie, 113(2), 163-176.

Isique Calderón, J., Morales, N., Quispe., R., \& Quispe, A. (2017). Aprovechamiento de residuos de pescado y crustáceos para obtención de productos bioactivos y funcionales.

Jordán, M., \& Casaretto, J. (2006). Capítulo XV Hormonas y Reguladores del Crecimiento: Auxinas, Giberelinas y Citocininas. In Fisiología Vegetal. Squeo, F, A., y Cardemil, L.

Karlova, R., \& de Vries, S. C. (2006). Advances in understanding brassinosteroid signaling.

Kessel Domini., A. (2018). Potencialidades del quitosano para la fresa. Usos en la mejora y conservación de los frutos. Cultivos Tropicales, 39(1), 134-142.

Kim, R. (2017). Antioxidant Effects of Salicornia bigelovii Seed Extracts. Korean Society for Biotechnology and Bioengineering Journal, 32(2), 140-145. https://doi.org/10.7841/ksbbj.2017.32.2.140

Kolbe, H., \& Stephan Beckmann, S. (1997). Development, growth and chemical composition of the potato crop (Solanum tuberosum L.). II. Tuber and whole plant. Potato Research, 40(2), 135153. https://doi.org/10.1007/BF02358240

Kraidees, M., Abouheif, M., Al-Saiady, M., Tag-Eldin, A., \& Metwally, H. (1998). The effect of dietary inclusion of halophyte Salicornia bigelovii Torr on growth performance and carcass characteristics of lambs. Animal Feed Science and Technology, 76(1), 149-159.

Kumar, M. (2000). A review of chitin and chitosan applications. Reactive and Functional Polymers, 46(1), 1-27.

Lim, D. H., Choi, D., Kim, S. M., Piao, Y. L., Choi, O. Y., Lim, G. S., .. Cho, H. (2017). Hypolipidemic and antioxidant effects on hypercholesterolemic rats of polysaccharide from Salicornia bigelovii seed. Korean Journal of Chemical Engineering, 34(3), 787-796. https://doi.org/10.1007/s11814-016-0335-8

Lira Saldivar, R. (2003). Fisiología Vegetal (E. Trillas., Ed.). México, D. F.

Liu, J., Tian, S., Meng, X., \& Xu, Y. (2007). Effects of chitosan on control of postharvest diseases and physiological responses of tomato fruit. Postharvest Biology and Technology, 44(3), 300-306.

Lizárraga, E., Torres, I., Moreno, E., \& Miranda, S. (2011). Protección contra estrés biótico inducida por quitosán en plántulas de maíz (Zea mays L.). Revista Mexicana de Ciencias Agrícolas, 2(6), 813-827.

López-Corona, B., Mondaca-Fernandez, I., Gortares-Moroyoqui, P., Holguín Peña, J., MezaMontenegro, M. M., De, J., ... Rueda-Puente, E. O. (2019). Revisión [Review] TÉCNICA DE ESQUEJES EN AGRICULTURA: UNA ALTERNATIVA A LA VANGUARDIA † [TECHNIQUE OF CUTTING IN AGRICULTURE: AN ALTERNATIVE AT THE 
VANGUARD]. Tropical and Subtropical Agroecosystems, 22, 505-517.

López Ortega, J., Vhymeister, E., \& Rodríguez, R. (2018). Algas marinas: una biomasa subutilizada como fuente de precursores petroquímicos. https://doi.org/10.24133/cctespe.v13i1.734

Manousaki, E., \& Kalogerakis, N. (2011). Halophytes present new opportunities in phytoremediation of heavy metals and saline soils. Industrial and Engineering Chemistry Research, 50(2), 656660. https://doi.org/10.1021/ie100270x

Mármol, Z., Gutiérrez, E., Páez, G., Ferrer, J., \& Rincón, M. (2004). Desacetilación termoalcalina de quitina de conchas de camarón. Multiciencias, 4(2), 1-9.

Mazuela Águila, P. (2013). Agricultura en zonas áridas y semiáridas. Idesia (Arica), 31(2), 3-4.

Mejía, B., Álvarez, A., \& Luna, B. (2011). Efectividad de un biofertilizante foliar sobre el cultivo de frijol común (Phaseolus vulgaris), bluefields. Ciencia e Interculturalidad, 8(4), 128-140.

Molina, J. (2015). Desmineralización de la quitina utilizando ácido fosfórico para la obtención de quitosano y su aplicación en el cultivo de arroz. Universidad del Zulia. Venezuela.

Molina Zerpa, J., Colina, M., Rincón., D., \& Vargas, J. (2017). Efecto del uso de quitosano en el mejoramiento del cultivo del arroz (Oryza sativa $\mathrm{L}$. variedad sd20a). Revista de Investigación Agraria y Ambiental, 8(2), 151-165. https://doi.org/10.21162/PAKJAS/16.2011

Mondal, M., Puteh, A., \& Dafader, N. (2016). Foliar application of chitosan improved morphophysiological attributes and yield in summer tomato (Solanum lycopersicum). Pakistan Journal of Agricultural Sciences, 53(2), 339-344.

Morales, G. D., Dell'Amico, R. J., Jerez, M. E., Díaz, H. Y., \& Martín, M. R. (2016). Efecto del QuitoMax ${ }^{\circledR}$ en el crecimiento y rendimiento del frijol (Phaseolus vulgaris L.). Cultivos Tropicales, 37(1), 142-147.

Morzaria, H., \& Barocio, S. (2008). Vegetación terrestre (G. D. \& y E. E. (eds. ). Danemann, Ed.). Bahía de los Ángeles.

Murrieta, C., Ezquerra, J., Ocaño, V., Cinco, F., Torres, W., \& Márquez, E. (2015). Aislamiento y caracterización parcial de miosina del manto de calamar gigante (Dosidicus gigas). CyTAJournal of Food, 13(3), 392-399.

Muzzarelli, R. (1977). Enzymatic synthesis of chitin and chitosan. Occurrence of chitin (O. U. Pergamon Press, Ed.).

Panduro, P., Reátegui, R., Flores, J., \& Sánchez, J. (2017). EFFECT OF DIFFERENT CONCENTRATIONS FROM INDOLBUTIRIC ACID IN THE ROOTING OF PEGS OF Dipteryx micrantha Harms (SHIHUAHUACO) IN SUB IRRIGATION CAMERA, YARINACOCHA-UCAYALI. Repositorio de Revistas de La Universidad Privada de Pucallpa, 2(2).

Peña Datoli, M. (2016). Recubrimiento de semillas de maíz (Zea mays L.) con quitosano y alginato de sodio y su efecto en el desarrollo radical. Agrociencia, 50(8), 1091-1106.

Peniche C. (2006). Estudios sobre quitina y quitosana. La Habana Cuba.

Pérez Silva R. (1989). Influencia de diferentes niveles de Nitrógeno y poblaciones de plantas sobre los rendimientos de maíz (Zea mays L.). Agronomía Tropical, 27, 451-459.

Plascencia Jatomea, M., Olvera, M., Arredondo, J., Hall, G., \& Shirai, K. (2002). Feasibility of fishmeal replacement by shrimp head silage protein hydrolysate in Nile tilapia (Oreochromis niloticus L) diets. Journal of the Science of Food and Agriculture, 82(7), 753-759. https://doi.org/10.1002/jsfa.1092

Puente, M. E., Li, C., \& Bashan, Y. (2004). Microbial populations and activities in the rhizoplane of rock-weathering desert plants. II. Growth promotion of cactus seedlings. Plant Biology, 6(5), 643-650. https://doi.org/10.1055/s-2004-821101

Puentes, L. N. (2012). Resistencia sistémica adquirida mediada por el ácido salicílico. Biotecnología En El Sector Agropecuario y Agroindustrial, 10(2), 257-267.

Ramírez, V. H., Arcila, J. P., Jaramillo, Á. R., Rendón-S, J. R., Cuesta, G. G., Menza F, H. D., ... Peña Q, A. J. (2010). FLORACIÓN DEL CAFÉ EN COLOMBIA Y SU RELACIÓN CON LA DISPONIBILIDAD HÍDRICA, TÉRMICA Y DE BRILLO SOLAR. In Cenicafé (Vol. 61).

Reddy, B. M., Arul, J., Angers, P., \& Couture, L. (1999). Chitosan treatment of wheat seeds induces resistance to Fusarium graminearum and improves seed quality. Journal of Agricultural and Food Chemistry, 47(3), 1208-1216. https://doi.org/10.1021/jf981225k

Rivero, G., Guerrero, R., \& Ramírez, M. (2005). Enraizamiento de estacas de semeruco (Malpighia glabra L.). Revista de La Facultad de Agronomía, 22(1), 34-41. 


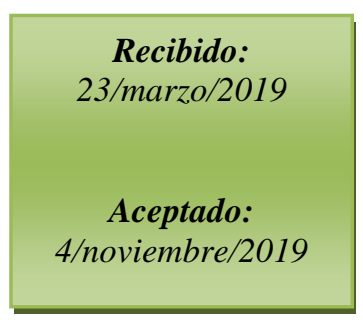

Rodríguez, A., Ramírez, M., Rivero, D., Bosquez, E., Barrera, L., \& Bautista, S. (2009). Propiedades químico-estructurales y actividad biológica de la quitosana en microorganismos fitopatógenos. Serie Horticultura, 15(3), 307-317.

Rueda-Puente, E., Castellanos, T., Troyo-Diéguez, E., Díaz De León-Alvarez, J. L., \& MurilloAmador, B. (2003). Effects of a Nitrogen-Fixing Indigenous Bacterium (Klebsiella pneumoniae) on the Growth and Development of the Halophyte Salicornia bigelovii as a New Crop for Saline Environments. Journal of Agronomy and Crop Science, 189(5). https://doi.org/10.1046/j.1439-037X.2003.00051.x

Rueda Puente, E., Beltrán, F., Ruíz, F., Valdez, R., García, J., Ávila, N., ... Murillo, B. (2011). Tropical and Subtropical Agroecosystems. Tropical and Subtropical Agroecosystems, 13(2), 157-167.

Rueda Puente, E., Villegas, J., Gerlach, L., Tarazón, M., Murillo, B., Troya, J., \& Preciado, P. (2009). Efecto de la inoculación de bacterias promotoras de crecimiento vegetal sobre la germinación de Salicornia bigelovii. Terra Latinoamericana, 27(4), 345-354.

Ruza, A., Skrabule, I., \& Vaivode, A. (2013). Influence of Nitrogen on Potato Productivity and Nutrient Use Efficiency. Natural, Exact, and Applied Sciences, 67(3), 247-253. https://doi.org/10.2478/prolas-2013-0043

Saborío, F. (2002). Bioestimulantes en fertilización foliar.

Sheikha, S., \& Al-Malki, F. (2011). Growth and chlorophyll responses of bean plants to the chitosan applications. European Journal of Scientific Research, 50(1), 124-134.

Slama, I., Abdelly, C., Bouchereau, A., Flowers, T., \& Savouré, A. (2015). Diversity, distribution and roles of osmoprotective compounds accumulated in halophytes under abiotic stress. Annals of Botany, 115(3), 433-447.

Sopalun., K., Thammasiri., K., \& Ishikawa., K. (2010). Effects of chitosan as the growth stimulator for Grammatophyllum speciosum in vitro culture. World Academy of Science, Engineering and Technology International Journal of Biotechnology and Bioengineering, 4(11), 828-830.

Statistical Analysis System. (2001).

Ventura, Y., Wuddineh, W., Myrzabayeva, M., Alikulov, Z., Khozin, I., Shpigel, M., \& Sagi, M. (2011). Effect of seawater concentration on the productivity and nutritional value of annual Salicornia and perennial Sarcocornia halophytes as leafy vegetable crops. Scientia Horticulturae, 128(3), 189-196.

Vera Alvarado, K., \& Parismoreno, L. (2017). Uso de quitosano en medios de cultivo para el desarrollo en la propagación in vitro de la Orquídea cattleya spp. Universidad de Guayaquil, Guayaquil Ecuador.

Villegas Espinoza, J. A., Rueda-Puente, E. O., Murillo Amador, B., Puente, M. E., Grimaldo Juárez, O., Avilés Marín, S. M., \& Ponce Medina, J. F. (2010). [EFECT OF THE INOCULATION OF Azospirillum halopraeferens and Bacillus amyloliquefaciens IN GERMINATION OF Prosopis chilensis]. In Tropical and Subtropical Agroecosystems (Vol. 12).

Warshay, B., Pan, J., \& Sgouridis, S. (2011, January). Aviation industry's quest for a sustainable fuel: Considerations of scale and modal opportunity carbon benefit. Biofuels, Vol. 2, pp. 33-58. https://doi.org/10.4155/bfs. 10.70

Wood, E. D., Armstrong, F. A. J., \& Richards, F. A. (1967). DETERMINATION OF NITRATE IN SEA WATER BY CADMIUM-COPPER REDUCTION TO NITRITE (Vol. 47).

$\mathrm{Xu}$, D., Hein, S., \& Wang, K. (2008). Chitosan membrane in separation applications. Materials Science and Technology, 24(9), 1076-1087. https://doi.org/10.1179/174328408X341762

Ziani, K., Ursúa, B., \& Maté, J. (2010). Application of bioactive coatings based on chitosan for artichoke seed protection. Crop Protection, 29(8), 853-859. 